\title{
CORRIGENDUM
}

\section{Variation in activity levels amongst dogs of different breeds: results of a large online survey of dog owners from the UK - CORRIGENDUM}

\author{
Emily Pickup ${ }^{1}$, Alexander J. German ${ }^{1,2}$, Emily Blackwell ${ }^{3}$, Mark Evans ${ }^{4}$ and Carri Westgarth ${ }^{1,5}$ \\ ${ }^{1}$ Institute of Veterinary Science, University of Liverpool, Neston, UK \\ ${ }^{2}$ Institute of Ageing and Chronic Disease, University of Liverpool, Neston, UK \\ ${ }^{3}$ School of Clinical Veterinary Science, University of Bristol, Langford, UK \\ ${ }^{4}$ Independent Veterinary Consultant, Guildford, UK \\ ${ }^{5}$ Institute of Infection and Global Health, University of Liverpool, Liverpool, UK
}

Journal of Nutritional Science (2021), vol. 10, e93, page 1 of 1

doi:10.1017/jns.2017.7. Published by Cambridge University Press, 17 April 2017

This article was published with errors in the first sentence of the section 'Off-lead exercise' on page 5 . The correct sentence is below.

\section{Off-lead exercise}

Some breeds were less commonly allowed off the lead in public $(\mathrm{P}<0 \cdot 001$; Table 1$)$, including: chow chow $(8,73 \%$ not let off the lead);

Siberian husky (67, 61\%); Pyrenean mountain $\operatorname{dog}(3,60 \%)$; Alaskan Malamute (31, 60\%); and St Bernard $(5,56 \%)$.

The authors apologise for the error.

\section{Reference}

Pickup, E., German, A., Blackwell, E., Evans, M., \& Westgarth, C. (2017). Variation in activity levels amongst dogs of different breeds: Results of a large online survey of dog owners from the UK. Journal of Nutritional Science, 6, E10. doi:10.1017/jns.2017.7

(C) The Author(s), 2021. Published by Cambridge University Press on behalf of The Nutrition Society. This is an Open Access article, distributed under the terms of the Creative Commons Attribution licence (http://creativecommons.org/licenses/by/4.0/), which permits unrestricted re-use, distribution, and reproduction in any medium, provided the original work is properly cited. 